\title{
FERTILITY VALUES AND ACCEPTANCE OF \\ POPULATION CONTROL AMONG COLLEGE STUDENTS*
}

\author{
Walter $G$. West \\ Virginia Commonwealth University
}

Eric D. Poole

Washington State University

\begin{abstract}
$\star \star$ This paper attempts to determine the effects of relevant social factors on college students' fertility values, examining how these variables and fertility values are associated with attitudes toward governmental population control. Having hypothesized that fertility values will vary by religion, social class, race and perception of overpopulation, the findings indicate that all the independent variables except race were related to fertility values in the predicted direction at low to moderate levels. The relatively low levels of association between these variables and fertility values suggest that the former yield little evidence from which fertility values can be predicted. However, fertility values are found to be a strong indicator of acceptance of governmental population control.
\end{abstract}

According to Blake (1969:522), "pressure on the federal government 'for action' to limit population growth in the United States has intensified greatly during the past 10 years, and at present such action is virtually unchallenged as an official national gnal." Thus, al though voluntary action is still widely accepted as an ideal, more and more observers argue that the urgency of overpopulation demands compulsion (Ehrlich, 1968; Hardin. 1968; Lamson, 1970; Prescott, 1969; Chasteen, 1971). Indeed, many authorities have concluded that population control can never be achieved as long as couples are free to have as many children as they so desire. Since the success of governmental action to limit population growth is in part dependent upon a couple's willingness to accept certain restrictions on their fertility behavior, knowledge of those factors that influence fertility behavior and those that affect acceptance of fertility control is greatly needed.

*A version of this paper was presented at the annual meetings of the Pacific Sociological Association, March 1974, San Jose, California.

**The above abstract is the editor's own addition. 
Unfortunately, with the emergence of a concern with the "population dilemma," researchers in the behavioral sciences have tended to focus attention on only a 1 imited aspect of the problem -- the determinants of family size. Numerous studies have concentrated primarily on the relationships between social characteristics and differentials in both actual and preferred family size. Given this focus on the social correlates of fertility behavior, it is surprising to note the paucity of research in this area on college populations. Moreover, no studies have attempted to relate fertility values to the broader problem of population control. Still, there is an obvious need to move toward a consideration of the interrelationships between determinants of fertility, fertility values, and receptivity to population control. Given these deficiencies in the prior research, the intent of this study is two-fold. First, we wish to determine the effect of relevant social factors on college students' fertility values. Second, we will examine how both these variables and fertility values are associated with attitudes toward governmental population control.

Research on differential fertility values of college students reveals that the smallest families are desired by those students who have no specific religious affiliation and by those who are relatively concerned about the problems of overpopulation (Westoff and Potvin, 1967; Darney, 1970). Al though there is minimal research on the association between race, social class, and the fertility values of college students, research on the general population has shown that non-whites have a higher fertility level than whites and that lower class families have a higher fertility level than middle and upper class families (Bogue, 1967; Blake, 1969; Smith and Zopf, 1970). Bogue (1967) finds, however, that a considerable part of the fertility variations between whites and non-whites may be explained by differences in levels of education. He notes, in fact, that the black college educated population has a lower fertility rate than their white counterparts. Likewise, in considering differential fertility patterns, we must note, along with Bogue (1967), that differences in educational attainment of various members of the upper, middle, and lower classes account for much of this variation.

To understand the impact of social class and racial factors on fertility desires of the college population, we shall examine the unique positions of both the black student and the student with a lower class background. It may be assumed that, through the socialization process endemic to college settings, these students become aware of and responsive to predominantly middle class attitudes and values. Further, they certainly recognize that their potential for upward mobility has been increased by their educational attainment. Thus, as Freeman (1963) notes, when these groups become cognizant of the consequences of fertility for both their present and future situations, acquire knowledge of birth control methods, and have the incentive to use them as one way of translating rising expectations into reality, a reduction in fertility may be expected.

The remainder of this review will attempt to demonstrate the importance of fertility values for an adequate understanding of receptivity to population control. Initially, cognitive balance models provide the basis for predicting that low fertility desires strengthen positive attitudes toward population control (Heider, 1958; Festinger, 1957). The empirical evidence certainly 
supports this prediction. Eisner, Tienhoven, and Rosenblah (1970) for example, found that students and faculty who desire two or less children were more likely to be in favor of limiting family size than those who prefer three or more children. A cognitive balance interpretation of these findings would assume that the student was seeking a balance between his attitudes toward fertility values and population control. Essentially, the balance model holds that attitudes toward objects, persons, and so on have positive or negative valences, and that there is a tendency for individuals to change attitudes which are not consonant in order to establish or maintain a balanced attitudinal state (Heider, 1958). Thus, we may hypothesize that the balancing process occurs in the following sequence. First, the individual who desires a large family forms a positive attitude toward high fertility. Second, during cognitive interaction, the individual evaluates the implications of fertility control for his fertility values. If he perceives fertility limitations as a potential threat, to his being able to have as many children as he desires, the individual is expected to view fertility control as negative toward high fertility. Third, since a balance occurs when there are either no negative signs or two negatives in the relation between the individual, high fertility, and fertility control, the individual is expected to form a negative attitude toward fertility control in order to maintain a consonant state.

Demonstrating the influence of this evaluative process, Brown (1972:520) suggests "that the value 'it is good to have a large family' may lead to the norm 'one ought to have as many children as possible.' The value and the norm supported by the value then in turn would have an influence on one's acceptance or rejection of contraception." Thus we are led to suggest that acceptance of population control is a function of fertility values.

On the basis of the above review of literature and preceding discussion, the following propositions provide an outline of the basic theoretical argument (see Figure 1).

Proposition 1: Students with religious affiliations will have higher fertility values than non-affiliated students.

Proposition 2: Whites will have higher fertility values than non-whites.

Proposition 3: The higher the social class, the greater the fertility values.

Proposition 4: Students who perceive the world to be overpopulated will have lower fertility values than those who do not.

Proposition 5: The greater the fertility values, the less the probability that the individual will accept government population control. 
METHODOLOGY

Sample

The data utilized for this study consisted of 215 anonymous questionnaires obtained from a random sample of students enrolled at Virginia Commonweal th University in the fall of 1972. Of these 215 questionnaires, 35.3 percent were completed by males and 64.7 percent by females; 93.5 percent of the students were white and 6.5 percent non-white. The educational level distribution was 38.6 percent freshmen, 26.5 percent sophomores, 17.7 percent juniors, 13.0 percent seniors, and 4.2 percent graduate or special students. The students overwhelmingly reported themselves to be from middle class families. Finally, 76.7 percent reported having a specific religious preference and 20.4 percent reported having no religious affiliation. The operational measures of the major variables considered in this study are described below.

Social Class

Hollingshead's Two Factor Index of Social Position (Hollingshead, 1957) was employed as a measure of the respondent's social class. This index ranks people on a class continuum based on the individual's occupation and education. Both education and occupation are given a scale score and factor weight. The product of these determines the individual's class position. Three categories were used for this classification: lower, middle, upper.

\section{Religious Affiliation}

The following criteria were used as a measure of religious affiliation. Those persons expressing a religious preference or identification (Protestant, Catholic, Jewish, and other) were categorized as having a religious affiliation. The non-affiliated category was composed of individuals who described themselves as being either an agnostic or an atheist.

Perception of Overpopulation

In order to measure the student's perception of overpopulation each respondent was asked the following question:

"Do you feel that the world, as it is today, is
overpopulated?"

Dichotomized responses were utilized to define those students perceiving or not perceiving overpopulation.

Fertility Values

A measure of fertility values was derived from several criteria dealing with student attitudes toward the number of children that members of various socioeconomic levels should have. Six categories were developed to provide a measure of the respondents ' own fertility desires and those projected for others. Those respondents indicating preferences for two or less children were classified as having low fertility values. Those preferring three or more children were identified as having high fertility values. 
Acceptance of Governmental Population Control

A summated scale was developed from responses to 22 statements to classify students according to their acceptance of governmental control. The statements presented differential family circumstances based on variations in race, income, and size for which governmental restrictions on couples' fertility were or were not proposed. Each statement was followed by four possible responses ranging from strongly agree to strongly disagree. A sample item from the scale is provided below:

The government should limit the number of children that a low income white couple with five children may have.

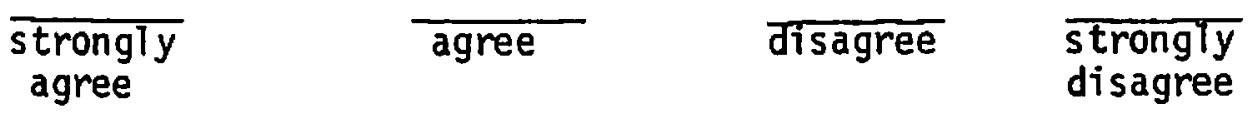

A principal-axis factor analysis was employed to evaluate the scale items for the existence of some underlying pattern of relationships. Principalaxis analys is provides a method of transforming a given set of variables into a new set of principal factors that are orthogonal (uncorrelated) with one another (Nie, Bent, and Hull, 1970). From this we may examine the importance of a given factor in terms of the proportion of the variance in the data it accounts for. Our initial factor matrix revealed that all twenty-two scale items loaded highly (high correlation coefficients) on one factor. The least amount of variance accounted for by the principal factor for any item in the scale was 36 percent $\left(r^{2}=.36\right)$. For the entire scale this factor accounted for 69 percent of the total variance $\left(r^{2}=.69\right)$. We thus considered our scale to be tapping one underlying dimension, a dimension which we conceptualized as acceptance of government population control. The respondents were then placed into dichotomous categories based on their summated scale scores. Those making scores of 44 and below were identified as having low acceptance of governmental control; those with scores ranging from 45 to 88 were classified as having high acceptance of governmental population control.

\section{FINDINGS}

Initially, a major consideration in testing our theoretical model concerns the differential effects of our independent variables upon fertility values. We have hypothesized that fertility values will vary by religion, social class, race, and perception of overpopulation. Our findings indicate that all of the independent variables except race were related to fertility values in the predicted direction at low to moderate levels. The low positive associations between religion and social class with fertility values support our expectations that students with religious affiliations have higher fertility values than do non-affiliated students and that upper class individuals want larger families than do their lower class peers. Furthermore, a direct link was found between perception of overpopulation and fertility values. This relationship indicates that students who perceive the world as being overpopulated are more likely to have lower fertility values than those students who do not have such a perception. In examining the relationship between race and fertility values, however, one finds a negative association (-.07). This evidence suggests that black students tend to 
prefer more children than do white students. Although this relationship is opposite from that predicted, it is even more surprising to find that the association between race and fertility values is only -.07 . Thus, it appears that a student's race has little impact on the number of children that he or she may desire. In light of these unexpected findings, the implications and possible interpretations for the failure of race to fit our model will be discussed in the conclusion section.

Second, as predicted, there is an inverse relationship between fertility values and acceptance of governmental population control $(=-.87)$. This high degree of association indicates that the fewer children a student desires, the greater his willingness is to accept population control. As previously noted, a student with high fertility values may perceive population control as a threat to his desire for a large family. For this cohort of the student population, control is potentially incongruous with high fertility wishes. On the other hand, those students wanting onty a few children may view population control as a relatively innocuous factor. For them population control poses few, if any, incompatibilities with low fertility values.

Our basic expectation is that the relationships between the independent variables, social class, religion, race, and perception of governmental population control, are indirectly related to one another through fertility values. If this is correct, one would expect that when the effects of fertility values are held constant, the relationships between the independent and dependent variables will be reduced to near zero. On the other hand, if these relationships are not altered to any great extent, a revision of our model would be required. When the effects of fertility values are partialed out, the relationships between race and religion with acceptance of governmental population control are slightly decreased. A similar control on the relationship between social class and acceptance of population control had no effect on the original association. Obviously, when cast as an intervening variable, fertility values appears to explain very little of the association between race, religion, social class, and acceptance of population control. For these sequences, the evidence does not support the proposed intervening linkages. Instead, we find that while both religion and social class are related to fertility values $(=.27$ and $=.10$, respectively), they appear to be unrelated to acceptance of governmental population control $(=.06$ and $=-.05)$. On the other hand, we find that al though race is r.ot related to fertility values $(=-.07)$ it is directly associated with acceptance of population control $(=.28)$. This latter finding indicates that white students express a greater will ingness to accept governmental population control than do black students. As noted earlier, an interpretation of the unexpected effects of race in our model will be presented in a later section.

Only the relationship between perception of overpopulation and acceptance of governmental population control suggests an intervening linkage through fertility values. In this case fertility values appear to explain nearly all of the association between the independent and dependent variables. Thus, with a control on fertility values, the original bivariate relationship between perception of overpopulation and population control was reduced to near zero. This result indicates that the fertility values of the students vary with their perception of overpopulation and that these fertiliity. values in turn affect their willingness to accept population control: 
Basically, we suggest that it is not the perception of overpopulation that influences acceptance of population control, but the low fertility desires which are fostered by such a perception.

As a final test of the predicted linkages we must determine the extent to which the association between fertility values and acceptance of population control is influenced by the independent variables. If this association is el iminated when social class, religion, race, or perception of overpopulation are controlled, the original relationship would be considered spurious. As reported in Table 2, the results for the tests of spuriousness show that none of the independent variables reduces the high relationship between fertility values and acceptance of population control. This strongly indicates that the original bivariate association is not a function of the antecedent effects of the independent variables. Indeed, one's fertility desires have a great impact on his willingness to accept governmental population control.

\section{CONCLUSIONS}

We have presented a model in which variations in religion, race, social class, and perception of overpopulation were viewed as determinants of fertility values. With the exception of race, all the independent variables were related to fertility values in the predicted directions. The surprising finding, however, is the relatively low levels of association between these variables and fertility values. Thus, contrary to the findings of previous studies, variations in basic background variables such as race, social class, and religion have little effect on preference for a large or small family.

An interpretation of these unexpected findings may be derived from Reid and Lyon (1972). They note that there is a scarcity of research dealing with the social and psychological variables associated with family size, especially in studies of college respondents. Although the literature indicates that race, religion and social class substantially affect the fertility desires of the general population, this expectation may not be applicable for a select college sample. Obviously, the college campus today resembles a quasi-melting pot that breeds a student subculture. It may be expected that certain variables which are salient for the general population fail to have an important influence in the college setting. Other variables endemic to this unique environment may, however, be operating, but they have yet to be measured in the research we have examined.

Perhaps the major finding that did not support expectations derived from previous research studies involves the lack of a relationship between race and fertility values. It has been previously reported that non-whites, when perceiving potential upward mobility through increased educational attainment, tend to reduce their fertility desires as a means of enhancing the ir opportunities (Freedman, 1963). Bogue (1969) provides some support for this assertion in his findings that college educated blacks have lower fertility rates than their white colleagues. The data showed, however, that non-whites and whites report similar fertility desires. These findings lend support to those who suggest an assimilation and acculturation model in attempting to explain the convergence of non-white and white fertility patterns to meet the norms and expectations held by their newly perceived reference group 
(Goldscheider and Uhlenberg, 1967). Thus, this evidence for a college population suggests that fertility values do not vary by race.

The expectation that acceptance of government population control is a function of fertility desires was strongly supported by the data. In considering the effects of fertility values on the relationships between social class, religion, race, and acceptance of population control, we find, however, that fertility values fail to serve as a causal link. For our college sample we find that the only variable which is at least moderately related to fertility values and which fits the proposed intervening model is perception of overpopulation. Nevertheless, while the independent variables supply little evidence from which we may predict fertility differentials, fertility values are found to be an exceptionally strong predictor of acceptance of governmental population control. Thus our basic concern in examining one's acceptance of population control appears to depend upon those underlying dimensions functioning in the college student's environment that influence his fertility desires. The question involves not why one desires children but why he desires a certain number of children.

In summary, the significance of our findings involves the failure of prominent background variables such as social class, race and religion to affect substantially one's preference for low or high fertility. Possible areas of research, therefore, should include measures of the interactional and combined effects of these variables on fertility desires as they operate in the college student's social milieu.

\section{References}

Barnett, L. D.

1970 "U.S. population growth as an abstractly perceived problem." Demography 7:53-60.

Berelson, $B$.

1969 "Beyond family planning." Science 163:533-542.

Blake, J.

1967 "Family size in the 1960's - A baffling fad?" Eugenics Quarterly 14:60-73.

1969 "Population policy for Americans: Is the government being misled?" Science 164:522-529.

Bogue, D. J.

1969 Principles of Demography. New York: John Wiley and Sons, Inc.

Brown, L.

1972 "Race, value orientations and fertility." In Stephen Biehn et al (eds.) Proceedings of the Second Annual Alpha Kappa Del ta Sociological Research Symposium. Richmond, Va.: Virginia Commonweal th University.

Chasteen, E. R.

1971 The Case for Compulsory Birth Control. Englewood Cliffs, N.J.: Prentice-Hall. 
Cooper, L.

1957 "Predisposition toward parenthood: A comparison of male and female students." Sociology and Social Research 42:31-36.

Darney, P. D.

1970 "Attitudes of married college students on over-population and family planning." U.S. Public Heal th Reports 85:412-418.

Davis, J. A.

1967 A partial coefficient for Goodman and Kruskal's gamma." Journal of the American Statistical Association 62:189-193.

1971 Elementary Survey Analysis. Englewood Cliffs, N.J.: Prentice-Hall.

Ehrlich, P. R.

1968 The Population Bomb. New York: Ballantine Books, Inc.

Eiser, T., Ari Van Tienhoven and F. Rosenblatt

1970 "Population control, sterilization and ignorance." Science $167: 1-33$.

Festinger, L.

1957 A Theory of Cognitive Dissonance. Evanston, Ill.: John Wiley and Sons, Inc.

Flanagan, J. C.

1939 "A study of psychological factors related to fertility." Proceedings of the American Philosophical Society 80:513-523.

Freedman, D. S.

1963 "The relation of economic status to fertility." American Economic Review 53:414-426.

Goldscheider, C. and Peter R. Uhlenberg

1969 "Minority group status and fertility." American Journal of Sociology 74:361-372.

Hardin, $G$.

1968 "The tragedy of the commons." Science 162:1243-1248.

Heider, F.

1968 The Psychology of Interpersonal Relations. New York: John Wiley and Sons, Inc.

Holl ingshead, A. B.

1957 "Two factor index of social position." In Charles Bonjean, Richard Hill and S. Dale Mclemore (eds.) Sociological Measurement: An Inventory of Scales and Indices. San Francisco: Chandler Publishing Co.

Kiser, C. V. (ed.)

1962 Research in Family $\mathrm{Planning.} \mathrm{Princeton:} \mathrm{Princeton} \mathrm{University}$ Press.

Lamson, R.W.

1970 "Federal action for population policy - What more can we do now?" Bio Science 20:854-857. 
Nie, N., D.,Bent and C $\mathrm{C}, \mathrm{Hull}$

-1970 Statistical Packáge' for the "Social'Sciences. New York: McGrawHil1 Book Co.

Prescott, D. M.

1969 "An editorial." Bio Science 19:205.

Rabin, A. I.

i965 "Motivation for parenthood." Journal of Projective Techniques and Personal ity Assessment 29:405-411.

Rainwater, L.

1965 Family Design: Marital Sexuality, Family Size and Contraception. Chicago: Aldine Publishing Co.

Reid, S. and D. L. Lyon

1972 Population Crisis: An Interdisciplinary Perspective. Glenview, I11.: Scott, Foresman and Co.

Smith, T. L. and P. E. Zopf, Jr.

1970 Demography: Principles and Methods. Philadelphia: F. A. Davis Co.

Stycos, J. M.

1971 "Opinion, ideology and population problems - Some sources of domestic and foreign opposition to birth control." In Rapid Population Growth: Consequences and Policy Implications. Baltimore: The Johns Hopkins Press.

Westoff, C., et al.

1961 Family Growth in Metropolitan America. Princeton: Princeton University Press.

Westoff, C. F., R. G. Potter and P. C. Sagi

1963 The Third Child. Princeton: Princeton University Press.

Whelpton, P. K. and C. V. Kiser

1959 "Social and psychological factors affecting fertility." The Eugenics Review 51: 35-42. 
Fertility Values and Acceptance of Population Control 117

\section{Table 1}

Zero Order Correlation Matrix

(Gamma Coefficients)

\begin{tabular}{llrrrrrr}
\hline Variables & & $x_{1}$ & $x_{2}$ & $x_{3}$ & $x_{4}$ & $x_{5}$ & $x_{6}$ \\
\hline Race & $x_{1}$ & 1.00 & .67 & -.46 & .42 & -.07 & .28 \\
Social Class & $x_{2}$ & & 1.00 & -.28 & .22 & .10 & -.05 \\
Religion & $x_{3}$ & & 1.00 & -.38 & .27 & .06 \\
Perception of Overpopulation & $x_{4}$ & & & 1.00 & -.36 & .22 \\
Fertility Values & $x_{5}$ & & & & 1.00 & -.87 \\
Governmental Population Control & $x_{6}$ & & & & & 1.00 \\
& & & & & & & \\
\hline
\end{tabular}

Table 2

Partial Gamma Coefficients

Control Variable: Fertility Values $X_{5}$

$x_{1}$ Race

$\frac{\text { Governmental Population Control }}{.20}$

$X_{2}$ Social Class

$-.05$

$X_{3}$ Religion

.02

$X_{4}$ Perception of Overpopulation

.05

Test of Spuriousness

$$
\begin{aligned}
& x_{5} x_{6} \cdot x_{1}=-.84 \\
& x_{5} x_{6} \cdot x_{2}=-.80 \\
& x_{5} x_{6} \cdot x_{3}=-.77 \\
& x_{5} x_{6} \cdot x_{4}=-.83
\end{aligned}
$$


118 Kansas Journal of Sociology:

Figure 1

Predicted Linkages

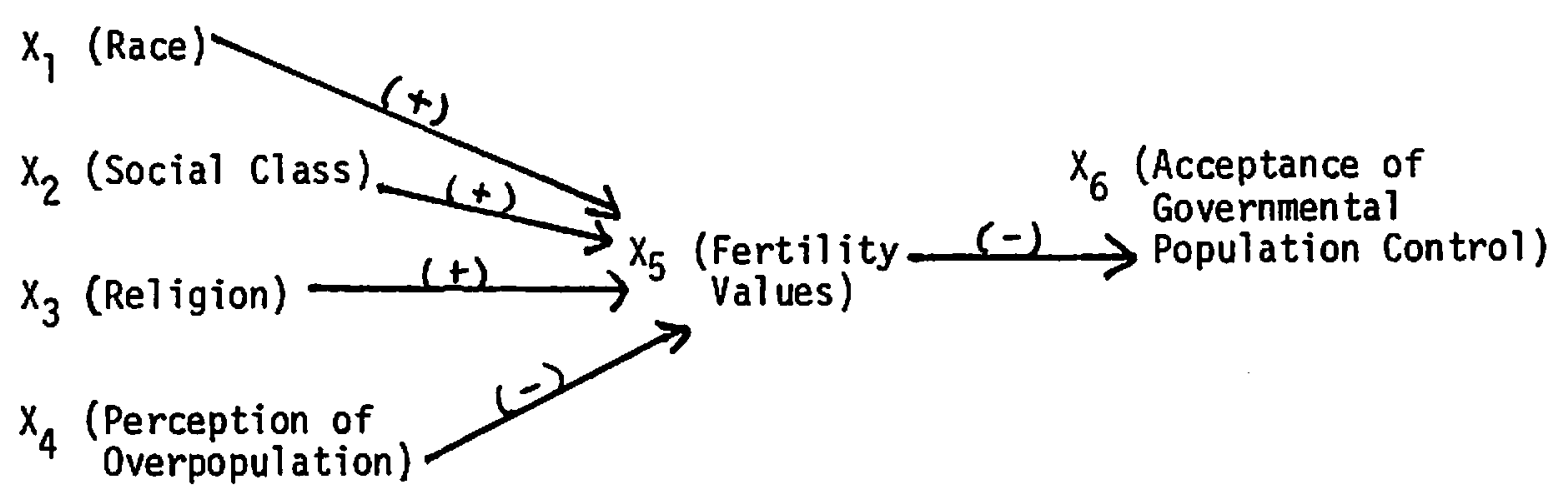

